\title{
Highly chiral-selective growth of single-walled carbon nanotubes with a simple monometallic Co catalyst
}

\author{
M. Fouquet, ${ }^{1,{ }^{*}}$ B. C. Bayer, ${ }^{1}$ S. Esconjauregui, ${ }^{1}$ R. Blume, ${ }^{2}$ J. H. Warner, ${ }^{3}$ S. Hofmann, ${ }^{1}$ R. Schlögl,${ }^{4}$ \\ C. Thomsen, ${ }^{5}$ and J. Robertson ${ }^{1}$ \\ ${ }^{1}$ Department of Engineering, University of Cambridge, Cambridge CB3 OFA, United Kingdom \\ ${ }^{2}$ Helmholtz-Zentrum Berlin for Materials and Energy, D-12487 Berlin, Germany \\ ${ }^{3}$ Department of Materials, University of Oxford, Oxford OXI 3PH, United Kingdom \\ ${ }^{4}$ Fritz-Haber-Institut der Max-Planck-Gesellschaft, D-14195 Berlin-Dahlem, Germany \\ ${ }^{5}$ Institut für Festkörperphysik, Technische Universität Berlin, 10623 Berlin, Germany
}

(Received 24 February 2012; revised manuscript received 24 May 2012; published 6 June 2012)

\begin{abstract}
We report on the growth of single-walled carbon nanotubes from a monometallic Co catalyst on an oxidized $\mathrm{Si}$ wafer support by the most simple growth recipe (vacuum annealing, growth by undiluted $\mathrm{C}_{2} \mathrm{H}_{2}$ ). Nevertheless, multiwavelength Raman spectroscopy and transmission electron spectroscopy show a remarkable selectivity for chiral indices and thus, e.g., high abundance with a single chirality representing $58 \%$ of all semiconducting tubes. In situ x-ray photoelectron spectroscopy monitors the catalyst chemistry during carbon nanotube growth and shows interfacial Co-Si interactions that may help to stabilize the nanoparticle/nanotube diameter. We outline a two-mechanism model explaining the selective growth.
\end{abstract}

DOI: 10.1103/PhysRevB.85.235411

PACS number(s): 81.07.De, 78.67.Ch

\section{INTRODUCTION}

The extraordinary electronic, thermal, and mechanical properties of single-walled carbon nanotubes (SWNTs) are closely related to their structure, which is uniquely defined via their chiral index $(n, m) .{ }^{1}$ Structural selectivity, ideally at the point of growth, is thus of key importance to unlock the full application potential for SWNTs. There have been a range of recent reports on the growth of SWNTs with a narrow $(n, m)$ distribution, in particular by catalytic chemical vapor deposition (CVD), which is the most versatile and promising synthesis technique both in terms of bulk production and direct device integration. ${ }^{2,3}$ This has typically been achieved by highly specific catalyst and/or support design, such as bimetallic systems ${ }^{4-9}$ and the use of mesoporous support, ${ }^{10-15}$ in combination with empirically optimized growth recipes. However, based on the immense CVD parameter space and the fact that such nanoscopic systems are very challenging to accurately characterize, ${ }^{16-20}$ the mechanisms that guide growth and lead to chiral selectivity remain largely unclear.

Here we explore chiral SWNT selectivity with a CVD process reduced to its most simple form. Our model system is based on Co thin films on an oxidized Si wafer support and simple vacuum annealing followed by a one-step exposure to undiluted $\mathrm{C}_{2} \mathrm{H}_{2}$. Despite its simplicity, multiwavelength Raman spectroscopy and transmission electron microscopy (TEM) indicate that the process leads to a surprisingly narrow set of SWNT chiral indices with a combined abundance of $65 \%$ for only three chiralities and about $80 \%$ of all SWNTs in the diameter interval of $0.74-0.89 \mathrm{~nm}$. We find that a single chirality accounts for $\sim 58 \%$ of the semiconducting tubes. In situ X-ray photoelectron spectroscopy (XPS) during growth reveals $\mathrm{Co}-\mathrm{Si}$ interactions which may stabilize the narrow catalyst particle distribution. Based on our observations, we attribute the selective growth to two driving mechanisms, namely nanoparticle size/stabilization and energy-selective SWNT cap formation.

\section{EXPERIMENTAL METHODS AND NANOTUBE MORPHOLOGY}

For catalyst preparation, we thermally evaporate a Co film of nominal $0.1 \mathrm{~nm}$ thickness onto $\mathrm{SiO}_{2}(200 \mathrm{~nm})$-coated $\mathrm{Si}$ wafers. We note that nominal $0.1 \mathrm{~nm}$ Co evaporation results in small nanoislands and not a continuous film. In a custom-built low-pressure chemical vapor deposition (lpCVD) chamber, we anneal the $\mathrm{Co}$ film at 600 or $700{ }^{\circ} \mathrm{C}$ in vacuum $\left(10^{-6} \mathrm{mbar}\right)$ followed by nanotube growth in pure $\mathrm{C}_{2} \mathrm{H}_{2}\left(10^{-3} \mathrm{mbar}\right)$. We use scanning electron microscopy (SEM,FEI XL30) and highresolution TEM (JEOL $4000 \mathrm{EX}$ at $80 \mathrm{kV}$, after scratch transfer of CNTs onto lacy carbon-coated copper mesh TEM grids) to characterize the resulting nanotube morphology and structure (Fig. 1).

Without removal from the support, the nanotubes are structurally characterized by Raman spectroscopy with eight different excitation energies ranging from 1.96 to $2.66 \mathrm{eV}$ (633 to $465 \mathrm{~nm}$ ). We employ two Raman systems: a confocal triple monochromator micro-Raman setup (DilorXY800) for 2.18 and 2.41-2.66 eV, and a Labram (HR800, Horiba Jobin Yvon) for 1.96 and $2.33 \mathrm{eV}$. Both systems are in backscattering geometry and the spectra are taken with a charge-coupled device (CCD).

The catalyst particle size after annealing was measured by atomic force microscopy (AFM, Veeco Dimension) and the evolution of surface chemistry was monitored during lpCVD by in situ XPS at the ISISS end station of the FHI-MPG at BESSY II. Details of data acquisition were reported elsewhere ${ }^{21-23}$ and are summarized in Appendix A.

\section{III. $(n, m)$ ASSIGNMENT AND ABUNDANCES}

We assign $(n, m)$ by converting radial breathing mode (RBM) peaks in the Raman spectra to diameters ${ }^{24}$ and compare these together with the excitation energies $E_{\text {laser }}$ to a theoretical Kataura plot ${ }^{25,26}$ (see Appendix B for details and limitations). We note that the difference of $E_{\text {laser }}$ and the transition energy 


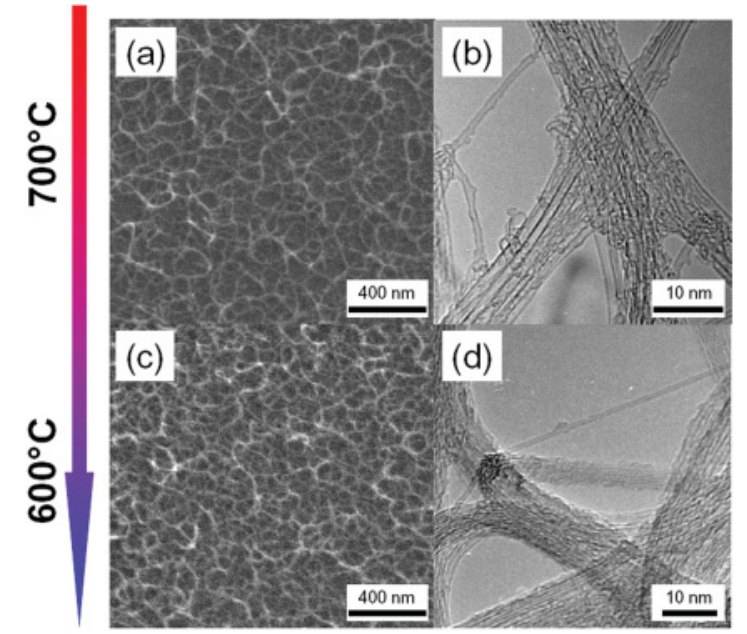

FIG. 1. (Color online) (a) SEM and (b) TEM image for growth with $\mathrm{C}_{2} \mathrm{H}_{2}$ at $700{ }^{\circ} \mathrm{C}$ and (c) SEM and (d) TEM image for $600{ }^{\circ} \mathrm{C}$.

$E_{\mathrm{ii}}$ could be an issue for the assignment. However, since nanotubes bundle during CNT CVD [Figs. 1(b) and 1(d)], the resonance window for $E_{\mathrm{ii}}$ broadens up to $0.12 \mathrm{eV}^{27}$ Consequently, the detection range for SWNTs increases to $1.84-2.78 \mathrm{eV}$ for $E_{\text {laser. }}$. Compared to the theoretical Kataura plot, ${ }^{25,26} 90 \%$ of all tubes are in the detection range. Figure 2 shows the resulting chiral maps for SWNTs grown at 600 and $700{ }^{\circ} \mathrm{C}$. The assigned $(n, m)$ indices are marked in red. The $700^{\circ} \mathrm{C}$ process yields 34 chiral indices [Fig. 2(a)] while $600^{\circ} \mathrm{C}$ narrows this to 27 [Fig. 2(c)]. Accordingly, the diameter range for $700{ }^{\circ} \mathrm{C}$ is $0.63-1.49 \mathrm{~nm}$ and decreases to $0.61-1.19 \mathrm{~nm}$ for $600{ }^{\circ} \mathrm{C}$ [Figs. 2(b) and 2(d), respectively].

For an individual $(n, m)$, the abundance $A_{(n, m)}$ is estimated semiquantitatively by

$$
A_{(n, m)} \propto \frac{I_{\text {exp }}(\mathrm{RBM})}{I_{\mathrm{Si}} \times I_{\text {theo }}(n, m)}
$$

with RBM intensity $I_{\text {exp }}(\mathrm{RBM})$, the Si peak intensity $I_{\mathrm{Si}}$, and the theoretical maximum Raman intensity $I_{\text {theo }}(n, m)$ from Ref. 25 . The grown samples have a very similar SWNT coverage, as shown in Figs. 1(a) and 1(c), and the same excitation is used for all SWNT samples. It can thus be expected that the influence of the environment (bundling, substrate, etc.) is constant. A noticeable change in the RBM intensity can hence be attributed to a higher abundance of that $(n, m)$ tube. The chiral maps in Fig. 2 also show the chiral abundance (column height) for the most intensive $(n, m)$. Assigned SWNT with $\leqslant 1 \%$ are in faded red. For the $700{ }^{\circ} \mathrm{C}$ growth, the prominent chiral indices are $(7,5)(14 \%),(7,6)(11 \%)$, and $(10,9)(11 \%)$. The ratio between metallic to semiconducting tubes is 1:3. Decreasing the temperature to $600{ }^{\circ} \mathrm{C}$ results in dominant $(6,5)(27 \%)$, $(6,6)(19 \%)$, and $(7,4)(19 \%)$. The ratio of semiconducting to metallic tubes changes to about 1:1 (46\%:54\%). Therefore, the $(6,5)$ tube represents more than half of the semiconducting tubes $(58 \%)$, and the $(6,6)$ and $(7,4)$ make up $70 \%$ of the metallic tubes. We note that the highly abundant tubes have large chiral angles close to armchair tubes. This is in agreement with the literature for both experiment ${ }^{4-9,12,14}$ and theory ${ }^{28-30}$ and may be related to higher growth rates for near-armchair tubes. ${ }^{31}$ Figure 3 shows the abundance as a function of SWNT diameter for both temperatures. We find that growth at $700{ }^{\circ} \mathrm{C}$ still has a broad diameter distribution, but for $600{ }^{\circ} \mathrm{C}$ about $80 \%$ of all tubes are found between 0.74 and $0.89 \mathrm{~nm}$. As mentioned earlier, the abundance estimation could be influenced by the mismatch of laser excitation and tube transition energies. However, cross-checking with TEM data (Fig. 1) supports the diameter ranges found with the Raman abundance estimation. The SWNT diameters are calculated by measuring the distance between two sidewalls using the IMAGEJ software and are in the range of $0.70-1.44 \mathrm{~nm}$ for $700{ }^{\circ} \mathrm{C}$ and $0.65-0.82 \mathrm{~nm}$ for $600{ }^{\circ} \mathrm{C}$. Both diameter ranges are in good agreement with the Raman results. We note that from neither TEM nor Raman did we find indications for the presence of multi- or doublewalled CNTs, nor did we find significant amorphous carbon contamination.

\section{STATE OF THE CATALYST}

Metal nanoparticles play a key role in controlling SWNT growth. They act as a nucleation site and simultaneously determine the tube diameter. ${ }^{15-18,32,33}$

To assess the size of the Co nanoparticles, AFM measurements [Fig. 4(top)] were done on the particles formed by $0.1 \mathrm{~nm}$ Co films during vacuum pretreatment at both temperatures. Figure 4(a) shows the height distributions of the annealed films and also displays the average height value for a bare $\mathrm{SiO}_{2}$ wafer, which also has a small amount of intrinsic roughness (RMS roughness $\sim 0.2 \mathrm{~nm}$ ). At $700^{\circ} \mathrm{C}$, the distribution exhibits a maximum at $1.5( \pm 0.3) \mathrm{nm}$, which decreases at $600{ }^{\circ} \mathrm{C}$ to $1.3( \pm 0.2) \mathrm{nm}$. Subtracting the average height of bare $\mathrm{SiO}_{2}$ $(\sim 1 \mathrm{~nm})$, we thus estimate average nanoparticle heights of 0.5 $( \pm 0.3) \mathrm{nm}$ for $700{ }^{\circ} \mathrm{C}$ and $0.3( \pm 0.2) \mathrm{nm}$ for $600{ }^{\circ} \mathrm{C}$. During AFM measurements, the samples are oxidized from exposure to ambient air, but during growth they are actually reduced to a metal (see XPS below) and thus shrink in volume [see Fig. 4(b)]. Considering a Pilling-Bedworth ratio of $\sim 2$ for Co oxide ${ }^{34}$ and assuming hemispherical particles on the $\mathrm{SiO}_{2}$, the AFM-extracted particle radii $r$ are in reasonable agreement with the tube diameters $d$ in Fig. 3 .

The particle sizes also correlate well with the observed nanotube diameter trend of a narrower distribution around a smaller average tube diameter for lower CVD temperatures (Fig. 3).

The chemical state of the catalyst is of key importance for successful CNT CVD. ${ }^{15-17,32}$ Therefore, we evaluate the state of the Co film during nanoparticle formation and SWNT growth by in situ XPS. For these experiments, air-transferred, silica-supported $0.6 \mathrm{~nm}$ Co films were investigated under the same lpCVD conditions as above. The thicker Co film was chosen for a better XPS signal but at the cost of somewhat reduced CNT yield (see Appendix C). The as-loaded Co film is oxidized in what appears to be mainly $\mathrm{CoO}$ [Fig. 5(bottom)]. ${ }^{35}$ Upon heating to $600{ }^{\circ} \mathrm{C}$ in vacuum, the Co film reduces to $\mathrm{Co}^{0}$, as evidenced by the peak at $778.2 \mathrm{eV}$ in the $\mathrm{Co} 2 p_{2 / 3}$ region, ${ }^{36}$ with some residual oxygen components remaining. The film splits into nanoparticles, indicated by an increasing Si signal [Fig. 5(middle)].

Interestingly, besides the $\mathrm{SiO}_{2}$ at $103.9 \mathrm{eV}$ upon heating ${ }^{37}$ we observe the appearance of additional peaks in both the 


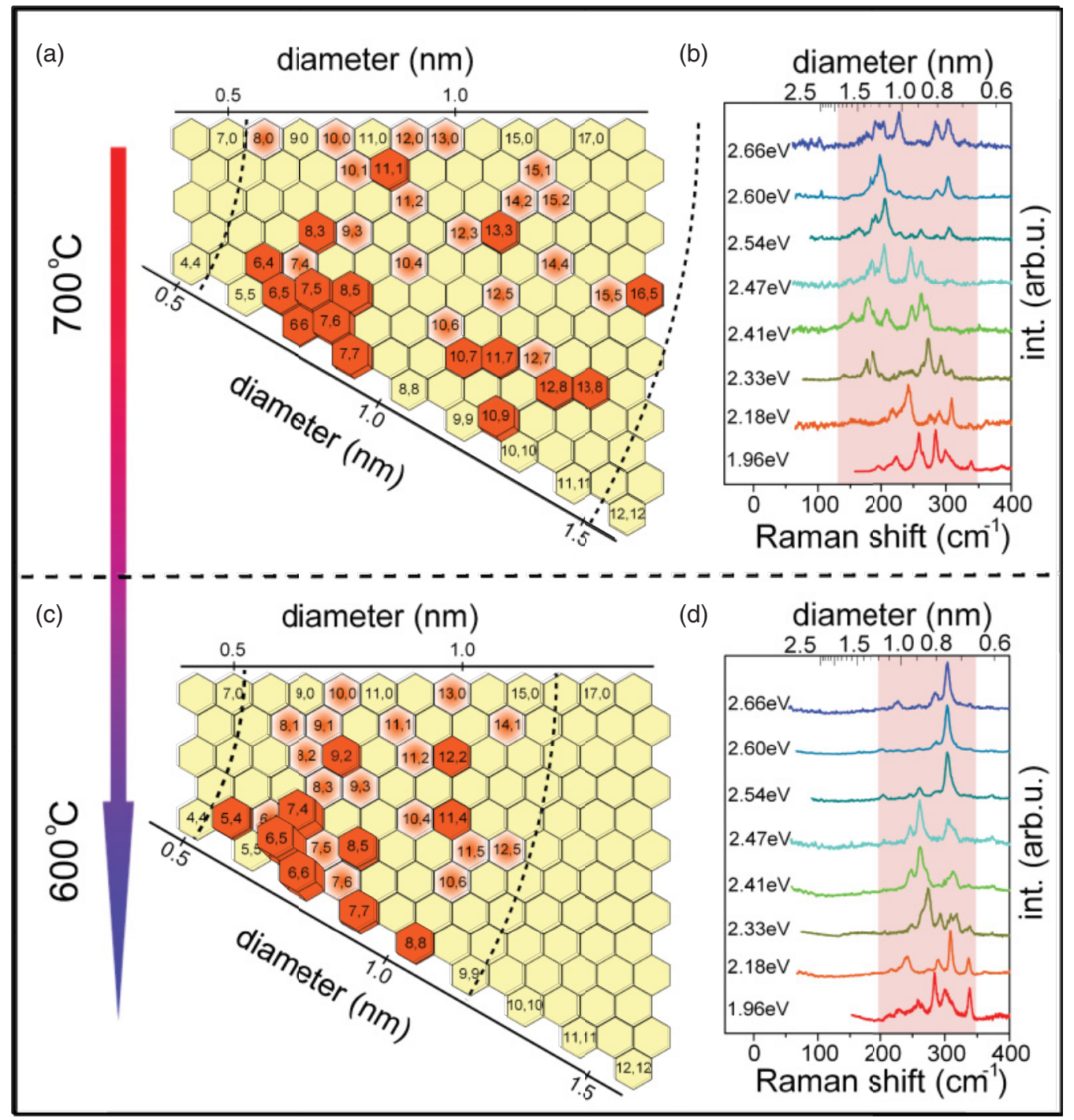

FIG. 2. (Color online) Chiral maps for growth at $700{ }^{\circ} \mathrm{C}$ (a) and $600{ }^{\circ} \mathrm{C}$ (c). Assigned chiral indices $(n, m)$ are marked in red. Abundance estimations for individual $(n, m)$ are shown by column height [for a numerical table of $(n, m)$ abundances, see Appendix B]. Assigned SWNTs with an abundance of $\leqslant 1 \%$ are kept in faded red. Raman spectra taken on the SWNT grown at $700{ }^{\circ} \mathrm{C}(\mathrm{b})$ and $600{ }^{\circ} \mathrm{C}(\mathrm{d})$ show the diameter range by the shaded area.

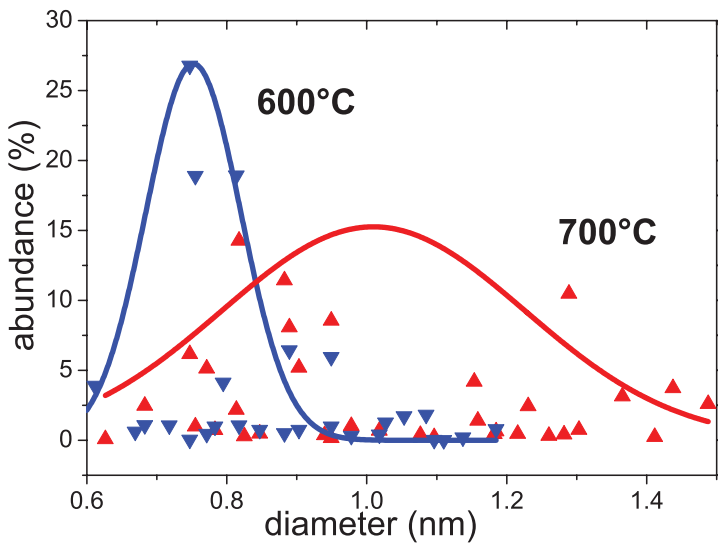

FIG. 3. (Color online) SWNT abundances vs diameter for growth at $700{ }^{\circ} \mathrm{C}$ (red) and $600{ }^{\circ} \mathrm{C}$ (blue) estimated from the Raman measurements. The lines are a guide for the eye.
Si $2 p$ (at 99.0 and $99.6 \mathrm{eV}$ ) and Co $2 p_{3 / 2}$ (at $778.9 \mathrm{eV}$ ) spectra. These components can be associated with $\mathrm{Co}-\mathrm{Si}$ interactions (e.g., amorphous $\mathrm{SiCo}$ or $\mathrm{CoSi}_{2}$ formation ${ }^{38}$ ). This suggests an interfacial reaction of the $\mathrm{SiO}_{2}$ support and the Co.

While $\mathrm{SiO}_{2}-\mathrm{Co}$ reactions are thermodynamically unfavorable, ${ }^{22,39}$ they can be triggered by the presence of impurities such as oxygen or surface water ${ }^{40}$ leading to silicide ${ }^{39}$ or silicate $e^{40-42}$ formation.

Interfacial reactions can stabilize nanoparticle distributions. ${ }^{15,22,43,44}$ We suggest that the silicide formation at the interface may be beneficial for the small catalyst diameter distribution that leads to the observed selective SWNT growth. ${ }^{45}$ During CVD, the chemical state of the Co and $\mathrm{Si}$ does not change significantly [Fig. 5(top)], indicating that metallic Co is the active catalyst for CNT growth. This is in agreement with previous in situ $\mathrm{XRD}^{46}$ and $\operatorname{Raman}^{32}$ measurements. Although the Co-Si interactions should be 


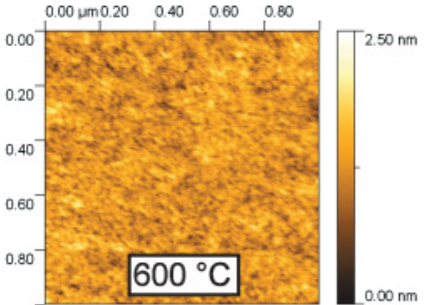

(a)

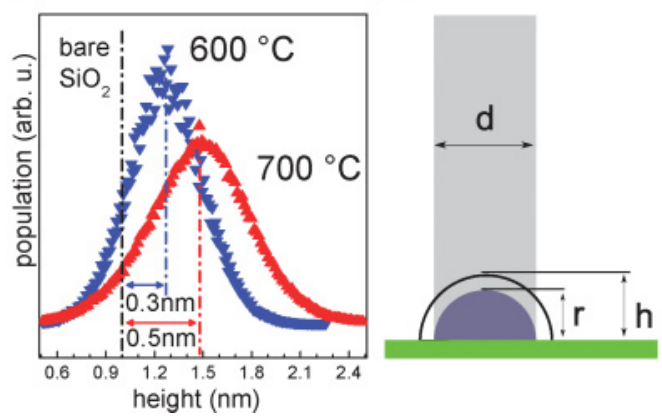

FIG. 4. (Color online) AFM images for both temperatures. Height distribution (a) found by AFM for the $0.1 \mathrm{~nm}$ Co film annealed in vacuum at $600{ }^{\circ} \mathrm{C}$ (blue) and $700{ }^{\circ} \mathrm{C}$ (red). The average height of a bare $\mathrm{SiO}_{2}$ substrate is also indicated. Schematic (b) of a SWNT with diameter $d$ nucleated by a nanoparticle with radius $r$. Oxidation in air increases the particle radius $r$ to $h$.

localized at the catalyst-support interface, they may also influence the $(n, m)$ selectivity.

\section{DISCUSSION}

We obtained a narrow chiral index distribution (Fig. 2) with an ultrathin Co film on an oxidized standard $\mathrm{Si}$ wafer support treated by vacuum annealing followed by $\mathrm{C}_{2} \mathrm{H}_{2}$ exposure. Since we limited the parameters for growth drastically, we are able to assess a more fundamental understanding of selective growth. Our data suggest at least two driving mechanisms.

First, the catalyst particles need the correct size for SWNT nucleation. This seems somewhat self-evident but is extremely important. In our case, the particle size is determined by two factors, namely the Co film thickness and the process temperature. The optimal Co film for SWNT growth was found to be a nominal $0.1 \mathrm{~nm}$ only. This remains true for other growth conditions we tested (not shown here) and is in good agreement with the literature. ${ }^{47-49}$ During annealing, the Co film splits into nanoparticles and the temperature becomes a more important factor for the particle size. ${ }^{50-52}$ The appearance of Co-Si interactions in XPS (Fig. 5) suggests a stabilization of the nanoparticles and thus prevents growth termination/multiwalled nanotubes by oversized particles. Thus even with our basic conditions, we are able to produce a nanoparticle size distribution that is both stable for growth and offers the correct particle size for SWNT nucleation.

The second mechanism for the selective growth is determining the chirality of the SWNT independent of the nanoparticle size. To illustrate this, we consider the $(6,6)$ and $(7,5)$ tubes, which both have a nominal diameter of $0.81 \mathrm{~nm}$ and hence could be nucleated by similar sized particles. For

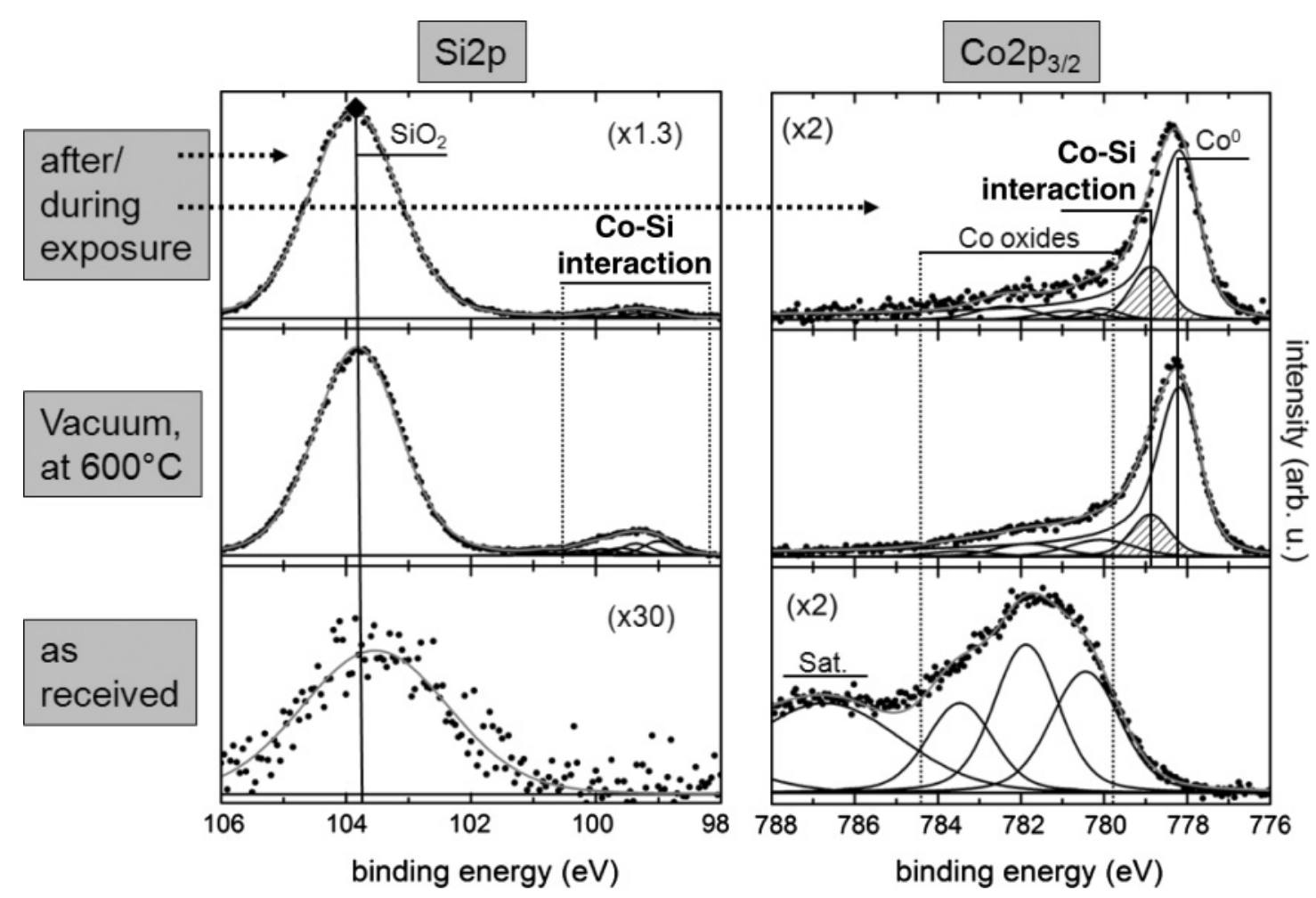

FIG. 5. In situ XPS for as-loaded (bottom), vacuum-annealed (middle), and during $\mathrm{C}_{2} \mathrm{H}_{2}$ exposure (top) of a $0.6 \mathrm{~nm}$ Co film. Note that the top left $\mathrm{Si} 2 p$ spectrum was actually acquired after growth at room temperature. Numbers in brackets are intensity multipliers. See Appendix A for XPS details. 
TABLE I. List of all assigned $(n, m)$ for both growth temperatures. The abundance is calculated by Eq. (1) and diameter $d=$ $\frac{a_{0}}{\pi} \times \sqrt{n^{2}+n m+m^{2}}$, with $a_{0}=2.46 \AA$. Type $s$ are semiconducting and type $m$ are metallic tubes. The RBM frequency $\omega_{\mathrm{RBM}}$ was found by fitting the Raman spectra.

\begin{tabular}{|c|c|c|c|c|c|c|c|c|c|}
\hline \multicolumn{5}{|c|}{ Growth at $600{ }^{\circ} \mathrm{C}$} & \multicolumn{5}{|c|}{ Growth at $700{ }^{\circ} \mathrm{C}$} \\
\hline ab. $(\%)$ & $(n, m)$ & $d(\mathrm{~nm})$ & & $\omega\left(\mathrm{cm}^{-1}\right)$ & ab. $(\%)$ & $(n, m)$ & $d(\mathrm{~nm})$ & & $\omega\left(\mathrm{cm}^{-1}\right)$ \\
\hline 26.78 & 6,5 & 0.747 & $s$ & 307.6 & 14.27 & 7,5 & 0.818 & $s$ & 284.3 \\
\hline 18.94 & 6,6 & 0.814 & $m$ & 284.3 & 11.44 & 7,6 & 0.882 & $s$ & 265.4 \\
\hline 18.89 & 7,4 & 0.755 & $m$ & 303.8 & 10.48 & 10,9 & 1.289 & $s$ & 184.7 \\
\hline 6.43 & 8,5 & 0.889 & $m$ & 261.3 & 8.56 & 7,7 & 0.949 & $m$ & 246.9 \\
\hline 5.96 & 7,7 & 0.949 & $m$ & 245.5 & 8.08 & 8,5 & 0.889 & $m$ & 261.1 \\
\hline 4.13 & 9,2 & 0.795 & $s$ & 289.4 & 6.16 & 6,5 & 0.747 & $s$ & 308.2 \\
\hline 3.89 & 5,4 & 0.612 & $s$ & 372.0 & 5.19 & 11,1 & 0.903 & $s$ & 258.4 \\
\hline 1.84 & 8,8 & 1.085 & $m$ & 216.6 & 5.12 & 8,3 & 0.771 & $s$ & 299.7 \\
\hline 1.71 & 11,4 & 1.053 & $s$ & 222.5 & 4.19 & 13,3 & 1.153 & $s$ & 206.1 \\
\hline 1.27 & 12,2 & 1.027 & $s$ & 227.2 & 3.72 & 13,8 & 1.437 & $s$ & 171.4 \\
\hline 1.08 & 6,4 & 0.683 & $s$ & 337.6 & 3.13 & 12,8 & 1.365 & $s$ & 176.0 \\
\hline 1.07 & 7,5 & 0.818 & $s$ & 284.5 & 2.59 & 16,5 & 1.488 & $s$ & 161.7 \\
\hline 1.07 & 8,2 & 0.718 & $m$ & 314.4 & 2.47 & 6,4 & 0.683 & $s$ & 337.8 \\
\hline 0.99 & 11,2 & 0.949 & $m$ & 241.1 & 2.44 & 11,7 & 1.231 & $s$ & 193.1 \\
\hline 0.99 & 10,0 & 0.783 & $s$ & 292.6 & 2.18 & 6,6 & 0.814 & $m$ & 285.5 \\
\hline 0.80 & 12,5 & 1.185 & $s$ & 202.4 & 1.41 & 10,7 & 1.159 & $m$ & 203.8 \\
\hline 0.75 & 9,3 & 0.847 & $m$ & 273.1 & 1.01 & 10,4 & 0.978 & $m$ & 234.3 \\
\hline 0.75 & 11,1 & 0.903 & $s$ & 257.8 & 0.98 & 7,4 & 0.755 & $m$ & 304.3 \\
\hline 0.62 & 8,1 & 0.669 & $s$ & 337.5 & 0.75 & 12,7 & 1.303 & $s$ & 182.7 \\
\hline 0.52 & 7,6 & 0.882 & $s$ & 265.1 & 0.73 & 10,0 & 0.783 & $s$ & 291.2 \\
\hline 0.46 & 8,3 & 0.771 & $s$ & 299.9 & 0.68 & 13,0 & 1.018 & $s$ & 228.4 \\
\hline 0.41 & 13,0 & 1.018 & $s$ & 229.3 & 0.64 & 12,5 & 1.185 & $s$ & 201.4 \\
\hline 0.32 & 10,4 & 0.978 & $m$ & 233.6 & 0.48 & 9,3 & 0.847 & $m$ & 271.3 \\
\hline 0.20 & 14,1 & 1.137 & $s$ & 206.0 & 0.47 & 15,1 & 1.216 & $s$ & 193.5 \\
\hline 0.04 & 9,1 & 0.747 & $s$ & 305.5 & 0.45 & 14,2 & 1.182 & $m$ & 200.5 \\
\hline 0.03 & 10,6 & 1.096 & $s$ & 215.5 & 0.41 & 14,4 & 1.282 & $s$ & 187.6 \\
\hline \multirow[t]{8}{*}{0.02} & 11,5 & 1.110 & $m$ & 211.9 & 0.38 & 12,3 & 1.077 & $m$ & 217.7 \\
\hline & & & & & 0.37 & 12,0 & 0.940 & $m$ & 247.6 \\
\hline & & & & & 0.32 & 15,2 & 1.260 & $s$ & 188.2 \\
\hline & & & & & 0.29 & 10,1 & 0.825 & $m$ & 274.3 \\
\hline & & & & & 0.25 & 15,5 & 1.412 & $s$ & 169.5 \\
\hline & & & & & 0.22 & 10,6 & 1.096 & $s$ & 215.8 \\
\hline & & & & & 0.15 & 11,2 & 0.949 & $m$ & 242.9 \\
\hline & & & & & 0.08 & 8,0 & 0.626 & $s$ & 363.1 \\
\hline
\end{tabular}

growth at $700{ }^{\circ} \mathrm{C}$, the $(7,5)$ is very abundant $(14 \%)$ and the $(6,6)$ only limited $(2 \%)$, but a decrease to $600{ }^{\circ} \mathrm{C}$ gives a contrary result $[(7,5)(1 \%)$ and $(6,6)(19 \%)]$. This indicates a dependence on temperature alone since all other parameters are constant.

For the nucleation of a SWNT, a cap condenses on the catalyst nanoparticle structure, and by adding carbon atoms to the rim of the cap the tube elongates. ${ }^{18,29,30,53,54}$ We speculate that the energy difference for the two temperatures can either result in direct constraints for cap formation energies ${ }^{28,53}$ leading to different caps or indirect constraints by slight deformations in the catalyst particle structure. ${ }^{18,50,55}$ Furthermore, the SWNT elongation or growth rate could be influenced and hence show different abundances. Both theory ${ }^{29,30}$ and experiment ${ }^{31}$ suggest a faster growth rate for SWNT at the armchair end compared to the zigzag end. But since both tubes in the example above are armchair or close-to-armchair tubes, the argument seems invalid. We thus attribute the different abundances to different SWNT nucleations and not growth rates.

Finally, we want to point out that the selectivity observed for our basic catalyst/support and basic growth conditions follows the same pattern as the more complex bimetallic catalysts ${ }^{4-9}$ or monometallic catalysts with mesoporous support. ${ }^{10-15}$ For all growth processes, we see a change in abundance from the $(6,5)$ tube at "low" temperatures to the $(7,5) /(7,6)$ tube at "high" temperatures, although the temperature parameters "low" and "high" depend strongly on the catalyst and/or support, which we attribute to different mobilities of the catalyst in the different systems.

In summary, we presented selective growth for a very basic catalyst system and growth conditions. We explained the chiral-selective growth as a two-step mechanism, in which a preselection in the form of the catalyst size is followed by an energy-dependent selective SWNT cap nucleation. 


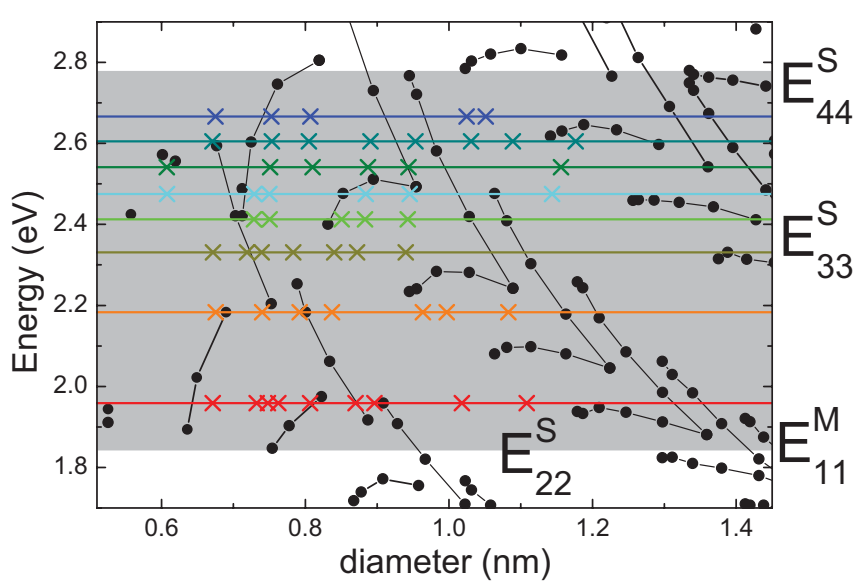

FIG. 6. (Color online) Theoretical Kataura plot (full circles) with experimental data points (colored crosses) for the SWNTs grown at $600{ }^{\circ} \mathrm{C}$. Colored horizontal lines are the excitation energies and the gray area is the SWNT detection range.

\section{ACKNOWLEDGMENTS}

We acknowledge funding from the EU Integrated Project "Technotubes" and the Helmholtz-Zentrum-Berlin BESSY II for provision of synchrotron radiation.

\section{APPENDIX A: XPS DETAILS}

The photoelectron spectra were taken at photon energies of $1020 \mathrm{eV}$ (Co 2p), $315 \mathrm{eV}$ (Si 2p), and $425 \mathrm{eV}(\mathrm{C} 1 s)$, respectively, with a spectral resolution of $0.3 \mathrm{eV}$. The kinetic energies of the electrons correspond to an electron mean free path $\lambda$ of $\sim 8 \AA$. The total XPS information depth is $\sim 2 \mathrm{~nm}$, that is, $95 \%$ of all detected electrons originate from $3 \lambda$. Background correction was performed by a Shirley background. The spectra were fitted following the Levenberg-Marquardt algorithm to minimize the $\chi^{2}$. Peak shapes were modeled by using asymmetric Doniach-Sunjic functions convoluted with Gaussian profiles. The accuracy of the fitted peak positions is $\sim 0.05 \mathrm{eV}$.

\section{APPENDIX B: $(n, m)$ ASSIGNMENT AND ABUNDANCES}

We followed the general route for an assignment of $(n, m)$ (see, e.g., Ref. 24) and fitted each RBM peak in the Raman spectra with a Lorentzian (see Table I). The $\omega_{\mathrm{RBM}}$ was then calculated to the corresponding diameter $d$ by $\omega_{\mathrm{RBM}}=C_{1} / d+C_{2}$ with constants $C_{1}$ and $C_{2}$ from Ref. 24 . The diameter $d$ was plotted with the excitation energy $E_{L}$ in a theoretical Kataura plot ${ }^{25,26}$ as shown in Fig. 6. The

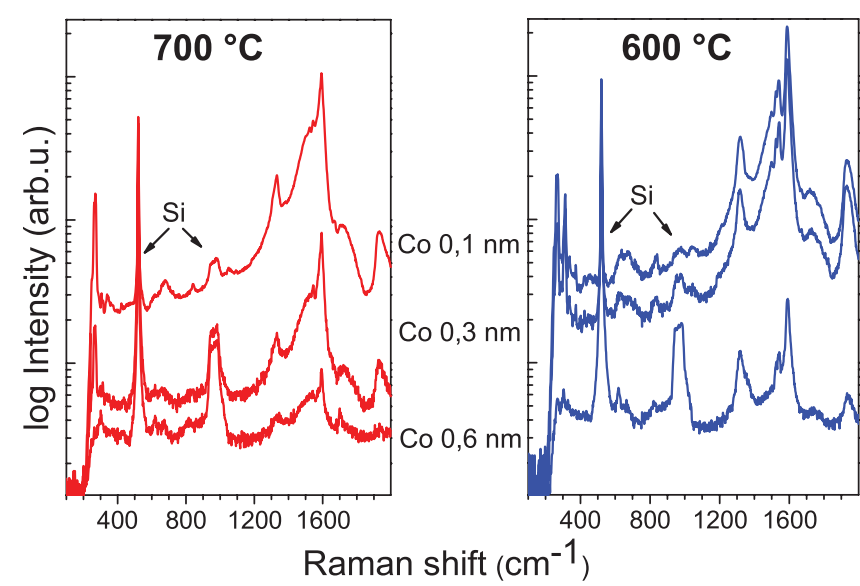

FIG. 7. (Color online) Raman overview for increasing Co thickness and both temperatures.

theoretical data have an empirical blueshift of $0.3 \mathrm{eV}$, which was attributed to self-energy and excitons. ${ }^{25}$ The gray area in Fig. 6 is the detection range mentioned in Sec. III, which is the result of RBM resonance window broadening of up to $0.12 \mathrm{eV}^{27}(n, m)$ assignment was then done by assessing the most likely candidates among the surrounding theoretical data points. We considered the difference of the excitation energy to the predicted transition energy, the diameter, the maximum Raman intensity predicted by theory, and the surrounding experimental data points for the same excitation energy similar to the pattern recognition method described in Ref. 24 . We always assigned the most likely candidate found with the criteria above, but we note that for larger diameters or isolated data points, the assignment has a higher uncertainty. An example of a difficult assignment is the $(11,5)$ and $(13,0)$ assigned to the RBM frequencies of 211.9 and $229.3 \mathrm{~cm}^{-1}$ observed for excitation at $1.96 \mathrm{eV}$. However, for smaller diameters and several surrounding experimental data points, we are confident in our assignments.

\section{APPENDIX C: CO-FILM THICKNESS EVALUATION}

To find the optimal thickness, we preevaluated three Co films including nominal $0.1,0.3$, and $0.6 \mathrm{~nm}$. Figure 7 compares Raman spectra for CNTs grown on these films for 600 and $700{ }^{\circ} \mathrm{C}$. Regardless of temperature, the strongest SWNT Raman signal is always seen for $0.1 \mathrm{~nm}$ Co. Although the signal weakens with increasing Co thickness, CNTs still grow (note the log intensity scale). In Fig. 7, the intensity of the second-order Si peak below $1000 \mathrm{~cm}^{-1}$ compared to the G mode at $1500-1595 \mathrm{~cm}^{-1}$ illustrates the SWNT coverage. The Si peak decreases and vanishes for the thinnest Co film for growth at $600{ }^{\circ} \mathrm{C}$. This, in conjunction with the SEM images (Fig. 1), confirms the strong SWNT coverage. *mf398@cam.ac.uk

${ }^{1}$ S. Reich, C. Thomsen, and J. Maultzsch, Carbon Nanotubes: Basic Concepts and Physical Properties (Wiley-VCH, Berlin, 2004).

${ }^{2}$ J. Robertson, G. Zhong, S. Hofmann, B. C. Bayer, C. S. Esconjauregui, H. Telg, and C. Thomsen, Diam. Rel. Mat. 18, 957 (2009).
${ }^{3}$ S. Esconjauregui, M. Fouquet, B. C. Bayer, C. Ducati, R. Smajda, S. Hofmann, and J. Robertson, ACS Nano 4, 7431 (2010).

${ }^{4}$ S. M. Bachilo, L. Balzano, J. E. Herrera, F. Pompeo, D. E. Resasco, and R. B. Weisman, J. Am. Chem. Soc. 125, 11186 (2003).

${ }^{5}$ G. Lolli, L. Zhang, L. Balzano, Y. T. N. Sakulchaicharoen, and D. E. Resasco, J. Phys. Chem. B 110, 2108 (2006). 
${ }^{6}$ Y. Murakami, Y. Miyauchi, S. Chiashi, and S. Maruyama, Chem. Phys. Lett. 377, 49 (2003).

${ }^{7}$ X. Li, X. Tu, S. Zaric, K. Welsher, W. S. Seo, W. Zhao, and H. Dai, J. Am. Chem. Soc. 129, 15770 (2007).

${ }^{8}$ Y. Miyauchi, S. Chiashi, Y. Murakami, Y. Hayashida, and S. Maruyama, Chem. Phys. Lett. 387, 198 (2004).

${ }^{9}$ W.-H. Chiang and R. M. Sankaran, Nat. Mat. 8, 882 (2009).

${ }^{10}$ H. Ago, S. Imamura, T. Okazaki, T. Saito, M. Yumura, and M. Tsuji, J. Phys. Chem. C 109, 10035 (2005).

${ }^{11}$ W. L. Wang, X. D. Bai, Z. Xu, S. Liu, and E. G. Wang, Chem. Phys. Lett. 419, 81 (2006).

${ }^{12}$ H. Wang, B. Wang, X. Y. Quek, L. Wei, J. Zhao, L. J. Li, M. B. Chan-Park, Y. Yang, and Y. Chen, J. Am. Chem. Soc. 132, 16747 (2010).

${ }^{13}$ N. Li, X. Wang, F. Ren, G. L. Haller, and L. D. Pfefferle, J. Phys. Chem. C 113, 10070 (2009).

${ }^{14}$ Y. Chen, L. Wei, B. Wang, S. Lim, D. Ciuparu, M. Zheng, J. Chen, C. Zoican, Y. Yang, G. L. Haller, and L. D. Pfefferle, ACS Nano 1, 327 (2007).

${ }^{15}$ M. He, A. I. Chernov, P. V. Fedotov, E. D. Obraztsova, E. Rikkinen, Z. Zhu, J. Sainio, H. Jiang, A. G. Nasibulin, E. I. Kauppinen, M. Niemelä, A. Outi, and I. Krause, Chem. Commun. 47, 1219 (2011).

${ }^{16} \mathrm{~S}$. Hofmann, R. Blume, C. T. Wirth, M. Cantoro, R. Sharma, C. Ducati, M. Havecker, S. Zafeiratos, P. Schnoerch, A. Oestereich, D. Teschner, M. Albrecht, A. Knop-Gericke, R. Schlögl, and J. Robertson, J. Phys. Chem. C 113, 1648 (2009).

${ }^{17}$ C. Mattevi, C. T. Wirth, S. Hofmann, R. Blume, M. Cantoro, C. Ducati, C. Cepek, A. Knop-Gericke, S. Milne, C. CastellarinCudia, S. Dolafi, A. Goldoni, R. Schloegl, and J. Robertson, J. Phys. Chem. C 112, 12207 (2008).

${ }^{18}$ H. Zhu, K. Suenaga, A. Hashimoto, K. Urita, K. Hata, and S. Iijima, Small 1, 1180 (2005).

${ }^{19}$ M. Picher, E. Anglaret, R. Arenal, and V. Jourdain, ACS Nano 5, 2118 (2011).

${ }^{20}$ M. Picher, E. Anglaret, R. Arenal, and V. Jourdain, Nano Lett. 9, 542 (2009).

${ }^{21}$ B. C. Bayer, S. Hofmann, C. Castellarin-Cudia, R. Blume, C. Baehtz, S. Esconjauregui, C. T. Wirth, R. A. Oliver, C. Ducati, A. Knop-Gericke, R. Schlögl, A. Goldoni, C. Cepek, and J. Robertson, J. Phys. Chem. C 115, 4359 (2011).

${ }^{22}$ B. C. Bayer, C. Zhang, R. Blume, F. Yan, M. Fouquet, C. Wirth, R. Weatherup, L. Lin, C. Baehtz, R. Oliver, A. Knop-Gericke, R. Schlögl, S. Hofmann, and J. Robertson, J. Appl. Phys. 109, 114314 (2011).

${ }^{23}$ B. C. Bayer, M. Fouquet, R. Blume, C. T. Wirth, R. S. Weatherup, K. Ogata, A. Knop-Gericke, R. Schlögl, S. Hofmann, and J. Robertson, J. Phys. Chem. C 116, 1107 (2012).

${ }^{24}$ J. Maultzsch, H. Telg, S. Reich, and C. Thomsen, Phys. Rev. B 72, 205438 (2005).

${ }^{25}$ V. N. Popov, L. Henrard, and P. Lambin, Phys. Rev. B 72, 035436 (2005).

${ }^{26}$ V. N. Popov and L. Henrard, Phys. Rev. B 70, 115407 (2004).

${ }^{27}$ C. Fantini, A. Jorio, M. Souza, M. S. Strano, M. S. Dresselhaus, and M. A. Pimenta, Phys. Rev. Lett. 93, 147406 (2004).
${ }^{28}$ S. Reich, L. Li, and J. Robertson, Chem. Phys. Lett. 421, 469 (2006).

${ }^{29}$ H. Dumlich and S. Reich, Phys. Rev. B 82, 085421 (2010).

${ }^{30}$ F. Ding, A. R. Harutyunyan, and B. I. Yakobson, Proc. Natl. Acad. Sci. USA 106, 2506 (2009).

${ }^{31}$ R. Rao, D. Liptak, T. Cherukuri, B. I. Yakobson, and B. Maruyama, Nat. Mater. 11, 213 (2012).

${ }^{32}$ M. Picher, E. Anglaret, and V. Jourdain, Diam. Relat. Mater. 19, 581 (2010).

${ }^{33}$ Y. Li, W. Kim, Y. Zhang, M. Rolandi, D. Wang, and H. Dai, J. Phys. Chem. B 105, 11424 (2001).

${ }^{34}$ R. Metz, J. Morel, H. Delalu, S. Ananthakumar, and M. Hassanzadeh, Mater. Res. Bull. 44, 1984 (2009).

${ }^{35}$ S. C. Petitto, E. M. Marsh, G. A. Carson, and M. A. Langell, J. Mol. Cat. A: Chem. 281, 49 (2008).

${ }^{36}$ J. J. Chang, C. P. Liu, T. E. Hsieh, and Y. L. Wang, Sur. Coat. Tech. 200, 3314 (2006).

${ }^{37}$ A. A. Galuska, J. C. Uht, and N. Marquez, J. Vac. Sci. Technol. A 6, 110 (1988).

${ }^{38}$ W. Platow, D. K. Wood, K. M. Tracy, J. E. Burnette, R. J. Nemanich, and D. E. Sayers, Phys. Rev. B 63, 115312 (2001).

${ }^{39}$ A. E. Morgan, K. N. Ritz, E. K. Broadbent, and A. S. Bhansali, J. Appl. Phys. 67, 6265 (1990).

${ }^{40}$ E. Kondoh, R. A. Donaton, S. Jin, H. Bender, W. Vandervorst, and K. Maex, Appl. Surf. Sci. 136, 87 (1998).

${ }^{41}$ N. Li, X. Wang, S. Derrouiche, G. L. Haller, and L. D. Pfefferle, ACS Nano 4, 1759 (2010).

${ }^{42}$ C. Wang, S. Lim, G. Du, C. Z. Loebicki, N. Li, S. Derrouiche, and G. L. Haller, J. Phys. Chem. C 113, 14863 (2009).

${ }^{43}$ S. Esconjauregui, B. C. Bayer, M. Fouquet, C. T. Wirth, C. Ducati, S. Hofmann, and J. Robertson, J. Appl. Phys. 109, 044303 (2011).

${ }^{44}$ P. B. Amama, C. L. Pint, L. McJilton, S. M. Kim, E. A. Stach, P. T. Murray, R. H. Hauge, and B. Maruyama, Nano Lett. 9, 44 (2009).

${ }^{45}$ Note that during heating, also small Co- and Si-carbide signals in the $\mathrm{C} 1 s$ (not shown here) emerge [matching to $100.2 \mathrm{eV}$ in $\mathrm{Si} 2 p$ (Ref. 38) and possibly also partly $778.9 \mathrm{eV}$ in Co $2 p$ (Ref. 38)]; we attribute the interactions to adventitious carbon from sample transport in air.

${ }^{46}$ J. P. Pinheiro, M. Schouler, and E. Dooryhee, Solid State Commun. 123, 161 (2002).

${ }^{47}$ S. Noda, Y. Tsuji, Y. Murakami, and S. Maruyama, Appl. Phys. Lett. 86, 173106 (2005).

${ }^{48}$ K. Kakehi, S. Noda, S. Maruyama, and Y. Yamaguchi, Jpn. J. Appl. Phys. 47, 1961 (2008).

${ }^{49}$ K. Kakehi, S. Noda, S. Maruyama, and Y. Yamaguchi, Appl. Surf. Sci. 254, 6710 (2008).

${ }^{50}$ Y. J. Oh, C. A. Ross, Y. S. Jung, Y. Wang, and C. V. Thompson, Small 5, 860 (2009).

${ }^{51}$ A. Geissler, M. He, J. M. Benoit, and P. Petit, J. Phys. Chem. C 114, 89 (2010).

${ }^{52}$ J. D. Carey, L. L. Ong, and S. R. P. Silva, Nanotechnology 14, 1223 (2003).

${ }^{53}$ S. Reich, L. Li, and J. Robertson, Phys. Rev. B 72, 165423 (2005).

${ }^{54}$ D. Schebarchov, S. C. Hendy, E. Ertekin, and J. C. Grossman, Phys. Rev. Lett. 107, 185503 (2011).

${ }^{55}$ O. Kitakami, H. Sato, Y. Shimada, F. Sato, and M. Tanaka, Phys. Rev. B 56, 13849 (1997). 